Vol. 6, No. 1, April 2018, pp. 9 13

\title{
Penerapan Strategi Marketing Public Relations Wake Up Hostel Dalam Mempertahankan Loyalitas Pengunjung
}

Cindiana Susanto ${ }^{1}$

${ }^{1}$ Program Studi Ilmu Komunikasi, Universitas Ahmad Dahlan, Indonesia

\begin{tabular}{l} 
Article Info \\
\hline Article history: \\
Received Jan 17, 2018 \\
Accepted Feb 3, 2018 \\
\hline
\end{tabular}

\section{Keywords:}

Wake Up Hostel

Strategi MPR Tripartid

Strategi media massa

Loyalitas Pengunjung

\begin{abstract}
Penelitian ini bertujuan untuk mengetahui strategi marketing public relations tripartid (push, pull, dan pass strategi) dan strategi media massa yang digunakan oleh Wake Up hostel Yogyakarta dalam meningkatkan loyalitas pengunjung,serta mengetahui hambatan yang muncul pada pelaksanaan strategi tripartid serta solusi yang didapat untuk mengatasi hambatan- hambatan tersebut. Metode yang digunakan oleh peneliti yaitu metode kualitatif, sebagaimana peneliti menjadi instrumen kunci dengan menggunakan tekhnik pengumpulan data, analisis data bersifat induktif. Penelitian ini dilakukan di Wake Up hostel Yogyakarta tepatnya di jalan Gandekan No.44, Sosromenduran, Gedong Tengen, kota Yogyakarta. Peneliti memerlukan waktu selama 3 bulan untuk menyelesaikan skripsi. Tekhnik pengumpulan data dalam skripsi ini yaitu menggunakan metode wawancara, observasi dan dokumentasi. Hasil yang diperoleh dari semua kegiatan strategi marketing public relations Wake Up hostel dalam meningkatkan loyalitas pengunjung yaitu telah memberikan efek positif pada hostel, dilihat dari meningkatnya loyalitas pengunjung yang telah berulang kali menginap di Wake Up hostel, tak hanya itu ia juga membewa pengunjung baru. Efek lain juga dapat dilihat dari bentuk-bentuk kegiatan yang hingga saat ini masih terlaksana. Artinya pengunjung cukup antusias dan loyal terhadap fasilitas dan pelayanan hingga kegiatan-kegiatan yang diselenggarakan oleh Wake Up hostel. Loyalitas mereka dapat diliat dari tingkat kesukaan, kepuasan dan kepercayaan yang diberikan oleh pengunjung sehingga akan berpengaruh terhadap loyalitas pegunjung tersebuh yang menyebabkan meningkatnya pemasukan dari Wake Up hostel itu sendiri. Dengan demikian dapat diambil kesimpulan bahwa, strategi marketing public relations Wake Up hostel Yogyakarta dalam meningkatkan loyalitas pengunjung sedah cukup efektif, walaupun belum sepenuhnya terlaksana dengan baik.
\end{abstract}

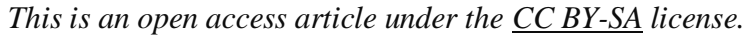

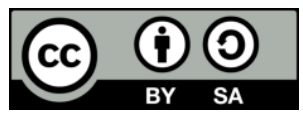

\section{Corresponding Author:}

Cindiana Susanto,

Program Studi Ilmu Komunikasi,

Universitas Ahmad Dahlan,

Email: cindiana@comm.uad.ac.id

\section{PENDAHULUAN}

Hostel merupakan suatu bisnis jasa akomodasi yang didalamnya terdapat unsur pelayanan, kenyamanan, serta fasilitas penginapan yang dibutuhkan bagi mereka yang menghendaki sarana penginapan untuk kepentingan keluarga maupun liburan, tetapi dari segi biaya lebih ramah kantong atau dalam artian lain hostel ini biasa disebut dengan hotel budged yang artinya biaya menginap per malam jauh lebih murah dibanding hotel pada umumnya. Salah satu dari sekian banyak penginapan sementara yang ada di yogyakarta yaitu Wake Up hostel yang tepatnya berada tepat di jalan Gandekan no 44, Sosromeduran,Gedong Tengen Yogyakarta. 
Letaknya yang sangat strategis menjadikan tempat favorite singgah bagi wisatawan, bahkan tak hanya wisatawan lokal saja tetapi wisatawan manca negara pun turut ramai berkunjung di Wake UP hostel. Wake Up hostel menyediakan segala fasilitas yang bagus dengan pelayanan yang sangat baik(Azizah \& Adawia, 2018).

Banyaknya penginapan di Yogyakarta maka perusahaan dituntut untuk dapat bersaing agar tidak kalah dari hotel- hotel yang lain. Hostel ini tidak hanya harus berfokus pada pemasaran yang menjadi pokok utama untuk menggait pengunjung, perusahaan juga dituntut untuk mempertahankan citra perusahaan serta mempertahankan loyalitas pengunjung agar tetap memilih dan merasa puas atas jasa yang ditawarkan serta tidak merasa kecewa atas pelayanan jasa yang telah dipilihnya untuk tempat singgah sementara selama berlibur. Pada penelitian ini analisis yang dilakukan dilakukan oleh peneliti terkait bagaimana strategi marketing public reations dari Wake Up hostel Yogyakarta dengan takhtik three ways strategy, yaitu pull strategy, pass strategy dan push strategy dan strategi media massa yang digunakan untuk meninkatkan loyalitas pengunjung. Metide yang digunakan oleh peneliti dalam menganalisis data tersebut dengan menggunakan metode kualitatf (Artiningtyas et al., 2014).

\section{METODE}

Dalam penelitian ini peneliti menggunakan metode Penelitian kualitatif. Penelitian berupaya untuk mendiskripsikan bagaimana strategi marketing yang dilakukan oleh Wake Up hostel Yogyakarta dalam meningkatkan loyalitas pengunjung (metode penelitian kuantitatif, kualitatif,dan R\&D, 2016). Untuk mengetahui strategi yang dilakukan oleh Wake Up hostel dalam meningkatkan loyalitas pengunjung menggunkanan strategi marketing public relations pull strategy, push strategy dan pass strategy dan dengan menggunakan stratei media massa. Metode ini dipilih karena sesuai dengan tujuan penelitian untuk mengetahui penerapan strategi public reations Wake Up hostel dalam meningkatkan loyalitas pengnjung . Objek dari penelitian ini adalah Wake Up hostel Yogyakarta. Teknik pengumpulan data yang digunakan untuk mengumpulkan data yaitu Observasi atau pengamatan yang dilakukan oleh peneliti secara langsung atau mengunjungi Wake Up hostel Yogyakarta. Yang kedua wawancara dengan humas dan 2 narasumber yang telah dipilih. Teknik analisis data yang digunakan dalam penelitian ini adalah dengan menggunakan deskriptif analisis dengan menggunakan teori strategi marketing public relations pull strategy pass strategy dan push strategy. Analisis ini digunakan untuk mengetahui penerapan strategi marketing public relations Wake Up hostel dalam meningkatkan loyalitas pengunjung (Sugiyono, 2016).

\section{HASIL DAN PEMBAHASAN}

Streategi marketing public relations Wake Up hostel Yogyakarta dalam meningkatkan loyalitas pengunjung. Menurut ruslan (2002: 253) Marketing Public Relations (MPR) merupakan proses perencanaan dan pengevaluasian program-program yang merangsang pembelian dan kepuasan konsumen melalui komunikasi mengenai informasi yang dapat dipercaya dan melalui kesan-kesan yang menghubungkan perusahaan dan produknya sesuai dengan kebutuhan, keinginan, perhatian dan kepentingan para konsumen. Dalam artian bahwa strategi yang digunakan HUMAS Wake Up hostel Yogyakarta yang dilakukan guna meningkatkan loyalitas pengunjung harus selalu mampu membuat strategi marketing dengan baik, dan sesui dengan kebutuhan yang sedang dihadapi oleh masyarakat, hal ini bertujuan untuk menarik sebuah pengujung agar mau memilih Wake Up hostel Yogyakarta sebagai tempat inap ketika berada di Yogyakarta.

Strategi pemasaran di Wake Up hostel Yogyakarta ini secara keseluruhan guna untuk mewujudkan pelanggan loyal dan merasakan kepuasan terhadap pelayanan maupun fasilitas yang diberikan oleh hostel, sehingga dari dasar pelanggan yang loyal tersebut omset yang dihasilkan menjadi meningkat. Dalam strategi pemasarannya untuk menciptakan loyalitas pengunjung ini merupakan bagian dari jalan utama perkembangan bisnis Wake Up hostel, yaitu dengan menggunakan Three Ways Strategy sebagai perwujudan dari kegiatan Marketing Public Relations dari strategi Public Relations, yaitu pull strategy (menarik), push strategy (mendorong), pass strategy (mempengaruhi) menurut Rosady Ruslan (2010:2).

Pull strategy merupakan salah satu strategi untuk menarik pelanggan atau konsumen, kedua Push strategy merupakan strategi untuk merangsang pelanggan atau konsumen untuk membeli produk atau jasa yang ditawarkan dengan mengguanakan pelayanan yang menarik sehingga konsumen akan tertarik untuk membeli atau penggunakan produk/ jasa yang ditawarkan, terakhir pass strategy yaitu strategi yang digunakan untuk membujuk konsumen atau pelanggan sehingga dapat mendukung tercapainya tujuan dari Marketing Public Relations. Strategi tersebut menerapkan seperti fasiltas kamar hostel standar yang sesuai kebutuhan para pengunjung. Selain itu Wake Up hostel Yogyakarta memiliki fasilitas seperti, kafe, wifi dan rooftop atau ruang kumpul keluarga melihat sunset dan sunrise sehingga seseorang yang menginap menjadi lebih nyaman, hal ini dilakukan agar kepuasan pengunjung tercipta. Sebuah mutu merupakan alat penentu kepuasan pengunjung sehingga mutu yang bagus dapat memberikan manfaat kepada hostel yaitu pemakaian ulang hostel oleh 
pengunjung atau dapat disebut juga loyalitas pengunjung terhadap hostel. Dalam menetapkan tarif hostel, Wake Up hostel selalu berusaha menetapkan harga yang dapat dijangkau oleh pengunjung dengan kualitas pelayanan dan fasilitas yang bermutu. Penentuan harga Wake Up hostel dalam menetapkan harga disesuaikan dengan segmen pasar. Untuk merangsang pengunjung, Wake Up hostel Yogyakarta juga memberikan potongan harga kepada pengunjung. Wake up Hoatel Yogyakarta ini memberikan potongan harga dan penghargaan kepada pengunjung maupun pengunjung yang telah beberapa kali menginap di Wake Up hostel Yogyakarta.

Peneliti mencoba menganalisis bahwa Marketing Public Relations (MPR) merupakan proses perencanaan dan pengevaluasian program-program yang merangsang pembelian dan kepuasan konsumen melalui komunikasi mengenai informasi yang dapat dipercaya dan melalui kesan-kesan yang menghubungkan perusahaan dan produknya sesuai dengan kebutuhan, keinginan, perhatian dan kepentingan para konsumen, Menurut ruslan (2002: 253). dengan menggunakan konsep Three Ways Strategy sebagai perwujudan dari kegiatan Marketing Public Relations dari strategi Public Relations, yaitu pull strategy (menarik), push strategy (mendorong), pass strategy (mempengaruhi) menurut Rosady Ruslan (2010:2). Oleh karena itu penulis menggunakan analisis Induksi yaitu menemukan teori dari data penelitian.

Semua bentuk upaya peningkatan strategi marketing public relations secara terus menerus dalam pandangan peneliti akan menjadikan calon pengunjung lebih dapat menikmati Wake Up hostel Yogyakarta, maka akan mampu memelihara loyalitas pelanggan hostel. Terkait dengan kepuasan pelanggan ini, sebagaimana hasil wawancara peneliti dengan beberapa pengunjung, secara garis besar mereka memang cukup merasa puas dan senang dengan fasilitas dan pelayanan Wake Up hostel Yogyakarta. Jika dikaitkan dengan unsur strategi marketing public relations Wake Up hostel juga sudah melakukan strategi marketing dengan konsep three keys strategy. Hal ini terlihat mulai dari menarik pengunjung, mendorong pengunjung dan mempengaruhi dengan fasilitas yang berkualitas, harga yang disesuaikan dengan kondisi pelanggan, lokasi hostel yang strategis, nyaman dan mudah dijangkau, promosi yang dilakukan sudah cukup maksimal dan event untuk mengundang banyak masyarakat dan pengunjung akan adanya Wake Up hostel itu sendiri.

Strategi media massa yang digunakan oleh wake up hostel dalam meningkatkan loyalitas pengunjung. Menurut Effendy(2003:65), media massa digunakan untuk berkomunikasi dengan jumlah banyak dan memiliki jarak yang jauh. Media massa yang sering digunakan dalam kehidupan sehari-hari umumnya adalah surat kabar, radio, televisi, internet, edukasi dan rekreasi, atau dalam istilah lain yaitu pendidikan, dan hiburan. Dengan demikian media massa dapat disebut juga dengan suatu alat yang digunakan untuk melakukan atau menyebarkan informasi dari komunikator ke komunikan, dan berjumlah banyak serta bersifat heterogen. Dengan adanya media massa yang lebih modern di zaman sekarang sangatlah memudahkan Wake Up hostel Yogyakarta untuk mempromosikan agar lebih dikenal oleh masyarakat luas. Media yang digunakan oleh Wake Up hostel yaitu, website Wake Up, instagram, facebook, twitter. Media yang dibuat tersebut sangatlah membantu hostel dalam mempromosikan keberadaan hostel itu sendiri, karena memiliki keutamaan dalam penyebaran pesan-pesan kepada masyarakat luas pengguna internet. Wake Up hostel Yogyakarta cenderung memilih menggunakan media massa internet dalam mempromosikan hostelnya dalam rangka meningkatkan loyalitas pengunjung. Internet merupakan salah satu wujud dari perpaduan antara arus komunikasi dengan perkembangan tekhnologi. Internet merupakan salah satu layanan berbasis web yang sangat digandrungi oleh masyarakat yaitu situs jejaring sosial. Dalam buku Ilmu Komunikasi Teori dan Praktek (Effendy, 2003:54) menegaskan ada beberapa fungsi dari media massa itu sendiri. Fungsi komunikasi massa secara umum yang pertama yaitu sebagai fungsi informasi, hal ini bertujuan untuk memberikan informasi bahwa media massa merupakan penyebar informasi bagi masyarakat. Kedua sebagai fungsi Pendidikan fungsi media massa ini merupakan sarana pendidikan bagi khalayaknya, karena media massa banyak memaparkan dan memberikan informasi yang bersifat mendidik. Salah satu pendidikan media massa yang pertama kali dilakukan untuk para masyarakat yaitu melalui pengajaran nilai, etika, serta aturan-aturan yang berlaku dalam bermedia massa. Ketiga yaitu fungsi Memengaruhi. Fungsi ini digunakan untuk memengaruhi peran-peran dalam lembaga tajuk/editorial, feature, iklan, artikel, dan sebagainya.

Pengaruh Loyalitas Pengunjung Wake Up Hostel Yogyakarta. Loyalitas pelanggan sebagai komitmen pelanggan terhadap suatu merek, toko, pemasok berdasarkan sikap yang sangat positif dan tercermin dalam pembelian ulang yang konsisten. Jadi pelanggan akan tetap komitmen terhadap sebuah produk atau jasa tersebut. Fandy Tjiptono (2000: 110). Artinya bahwa seorang pelanggan akan tetap memilih produk atau jasa yang ditawarkan, dalam kata lain pngunjung akan terus membeli atau menggunakan jasa dari sebuah perusahaan dalam jangka waktu yang cukup lama. Peneliti sudah melihat dengan respon pengunjung yang selalu mendukung adanya Wake Up hostel dan memberikan review yang positif terhadap hostel itu sendiri. Ulasan dari para pengunjung yang cenderung positif yang pada akhirnya membuat pengunjung akan loyal dan menginap di Wake Up hostel ketika berkunjung di Yogyakarta lagi. Loyalitas pengunjung juga berasal dari dari penilaian pengunjung terhadap kualitas yang diterimanya, hal tersebut berdasarkan keinginan apa yang telah terkonsep dalam pikiran pengunjung. keinginan tersebut muncul dari sebuah pelayanan dan fasilitas yang telah diterima sebelumnya yaitu pengalaman sebelumnya pernah menggunakan Wake Up hostel, serta berita 
dari mulut ke mulut yang sampai pada pelanggan. Penilaian tersebut akan menimbulkan kepuasan dan ketidak puasan terhadap pelanggan hostel. Pelanggan akan merasa puas jika kualitas yang diberikan telah sesuai atau bahkan melebihi keinginan pelanggan. Namun sebaliknya jika kualitas yang diberikan hostel kurang atau berada di bawah keinginan, maka pelanggan akan merasa kecewa.

Peneliti melihat bahwa beberapa pengunjung Wake Up hostel telah loyal teradap hostel tersebut. Hal ini diperkuat oleh data yang diperoleh peneliti dalam wawancara terhadap salah satu pengunjung Wake Up hostel yang telah dua kali menginap di Wake Up hostel ketika berlibur di Yogyakarta. Loyalitas pengunjung tersebut tak lain terbentuk dari faktor ramahnya para karyawan dalam pelayanan, fasilitas yang memadai hingga harga yang sangat terjangkau. Dengan itu pengunjung sangat tidak keberatan untuk menginap di Wake Up hostel Yogyakarta untuk kesekian kalinya. Tak hanya itu pengunjung juga membawa pengunjung baru yang nantinya dapat menciptakan loyalitas lagi terhadap hostel. Kedua, loyalitas pelanggan menurunkan biaya yang ditanggung perusahaan untuk melayani pelanggan hostel. Sebuah perusahaan mengeluarkan sejumlah biaya awal dalam usahanya guna menarik pelanggan baru. Biaya promosi, biaya pengoperasian, dan biaya pemasangan suatu sistem baru. Dalam jangka pendek, biaya-biaya itu sering kali melebihi revenue yang diperoleh dari pelanggan. Sehingga Wake Up hostel harus mampu mengembangkan strategi promosi agar benar-benar dapat menarik pengunjung, karena dengan strategi promosi yang baik dan tepat maka, akan dengan mudah menarik pelanggan. Setelah mendapatkan pelanggan maka, pelanggan akan diberikan fasilitas dan pelayanan yang memuaskan sehingga akan menciptakan loyalitas terhadap hostel. Terciptanya loyalitas pengunjung berarti meningkatkan pendapatan hostel, maka hal tersebut akan menutup biaya yang telah dikeluarkan untuk promosi hostel. Ketiga, loyalitas pelanggan meningkatkan komunikasi yang positif dari mulut ke mulut pengunjung. Para pelanggan Wake Up hostel Yogyakarta yang puas dan loyal kemungkinan besar akan memberikan rekomendasi sangat positif dari mulut ke mulut. Bentuk komunikasi ini terbukti membantu bagi para pelanggan baru yang berusaha membujuk dalam keputusan untuk menginap di Wake Up hostel. Oleh karena itu, suatu rekomendasi berfungsi sebagai suatu pendukung pemasaran dan membantu menurunkan pengeluaran perusahaan untuk menarik pelanggan baru. Manfaat terakhir dari loyalitas pelanggan adalah retensi karyawan. Karyawan Wake Up hostel Yogyakarta dipengaruhi oleh interaksi harian mereka dengan pelanggan hostel. Karena seseorang cenderung lebih suka bekerja dengan organisasi-organisasi agar pelanggannya puas dan tetap.

\section{KESIMPULAN}

Dalam meingkaatkan loyalitas pengunjung, Wake Up hostel Yogyakarta menggunakan strategi marketing public relations berupa Three Ways Strategy sebagai perwujudan dari kegiatan Marketing Public Relations, yaitu pull strategy (menarik), push strategy (mendorong), pass strategy (mempengaruhi) untuk meningkatkan loyalitas pengunjung. Wake Up hostel menggunakan strategi tersebut untuk meningkatkan loyalitas pengunjung dari strategi untuk menarik minat pengunjung dengan memberikan beberapa give away terhadap pengujung, maka pengunjung akan mulai tertarik terhadap Wake Up hostel, kedua menggunakan push strategi yaitu usaha untuk merangsang pengunjung dengan cara memberikan paket prom, dan yang terakhir menggunakan pass strategi yaitu sebuah strategi terahir yang akan memyebabkaan pengunjung akan tetap memilih Wake Up hostel sebagai tempat singgah, tidak hanya sekali bahkan berkali-kali. Tujuan dari strategi tersebut guna meningkatkan loyalitas penggunjung Wake Up hostel, tak hanya faktor strategi MPR itu namun strategi media massa yang digunakan Wake Up hostel sangat penting dalam mempromosikan adanya peberadaan hostel itu sendiri, agar leih dikenal oleh masyarakat luas. Sedangkan faktof lain yang dapat meningkatkan loyalitas pengunjung yaitu kualitas pelayanan dan fasilitas dari hostel pun mampu meberikan penilaian dari pengunjung sehingga terciptanya sebuah loyalitas pengunjung terhadap Wake Up hostel.

Hasil yang diperoleh dari semua kegiata strategi marketing public relations Wake Up hostel dalam meningkatkan loyalitas pengunjung yaitu dapat dilihat dari bentuk-bentuk kegiatan yang hingga saat ini masih terlaksana. Artinya pengunjung cukup antusias dan loyal terhadap fasilitas dan pelayanan hingga kegiatankegiatan yang diselenggarakan oleh Wake Up hostel. Loyalitas mereka dapat dilihat dari tingkat kesukaan, kepuasan dan kepercayaan yang diberikan oleh pengunjung sehingga akan berpengaruh terhadap loyalitas pegunjung tersebut yang menyebabkan meningkatnya pemasukan dari Wake Up hostel itu sendiri. 


\section{REFERENSI}

Abdul Rahin Bin Hamdan, Ahmad Johari Bin Hj Sihes, Jamaluddin Bin Ramli, Rosliza Binti Hamzah, Bernama, Ezaleila Mustafa, S., Hamid, S. A., Ibrahim, J., Nasrullah, R., Amir, O. A., Saidi, F. S., Adrianto, m, W., Mohd Hilmi Mohd Hashim, Muhd Zulkifli Ismail, Nik Farhan Mustafa, Mohamad, H., Paruzzaman, N. A., Does, H. O. W., Apply, I. T., ... Sonenthal, A. (2018). Media Sosial. Www.Moe.Gov.My.

Andreasen, A. R. (2002). Marketing social marketing in the social change marketplace. Journal of Public Policy and Marketing. https://doi.org/10.1509/jppm.21.1.3.17602

Artiningtyas, I., Minarsih, M. M., \& Hasiolan, L. B. (2014). Kepuasan Pelanggan. In Pengaruh Kualitas Layanan, Persepsi Harga dan Kepercayaan Terhadap Kepuasan Pelanggan.

Azizah, A., \& Adawia, P. R. (2018). strategi pemasaran. Cakrawala - Jurnal Humaniora. https://doi.org/10.31294/JC.V18I2.4117

Hurriyati, R. (2005). Bauran Pemasaran dan Loyalitas Konsumen. In Alfabeta Bandung.

PUBLIC RELATION BASED MODEL OF INTEGRATED MARKETING COMMUNICATIONS. (2016). UTMS Journal of Economics.

Sugiyono. (2016). Memahami Penelitian Kualitatif. Bandung: Alfabeta.

metode penelitian kuantitatif, kualitatif,dan R\&D, Alfabeta, cv. (2016). 